\title{
ESTÁGIO DE OBSERVAÇÃO E A FORMAÇÃO DA PROFESSORA DE MATEMÁTICA: ALGUMAS REFLEXÕES
}

\section{ARTIGO ORIGINAL}

PEREIRA, Diovane Nascimento ${ }^{1}$, SILVA, Américo Junior Nunes da ${ }^{2}$

PEREIRA, Diovane Nascimento. SILVA, Américo Junior Nunes da. Estágio de observação e a formação da professora de matemática: algumas reflexões. Revista Científica Multidisciplinar Núcleo do Conhecimento. Ano. 06, Ed. 11, Vol. 01, pp. 05-19. Novembro 2021. ISSN: 2448-0959, Link de acesso: https://www.nucleodoconhecimento.com.br/educacao/estagio-deobservacao

\section{RESUMO}

Este texto ambiciona relatar a experiência ocorrida durante o Estágio Curricular Supervisionado I, destinado à observação, e proposto como componente obrigatório do Curso de Licenciatura em Matemática da Universidade do Estado da Bahia, Campus VII. As atividades formativas do Estágio aconteceram em uma escola pública do Território de Identidade Piemonte Norte do Itapicuru, em uma turma de oitavo ano do Ensino Fundamental. Constituiu-se como questão norteadora para a escrita: como o movimento de estagiar, sobretudo em um estágio de observação,

${ }^{1}$ Estudante do Curso de Licenciatura em Matemática da Universidade do Estado da Bahia (UNEB), Campus VII.

2 Orientador. Doutor em Educação pela Universidade Federal de São Carlos (UFSCar); Mestre em Educação pela Universidade de Brasília (UnB); Especialista em Educação Matemática e Licenciado em Matemática pelo Centro de Ensino Superior do Vale do São Francisco.

RC: 100185

Disponível em: https://www.nucleodoconhecimento.com.br/educacao/estagio-de-observacao 
influencia a constituição da identidade docente? É objetivo, portanto, apresentar as reflexões originadas desse contato com a escola parceira, buscando olhar para esse espaço enquanto importante para o movimento de constituição da identidade docente. Foi possível, a partir das observações da realidade da escola, perceber e discutir sobre as questões envolta a prática de ensino do professor supervisor, o que recebe estudante estagiário, e das dificuldades enfrentadas pelos alunos no percurso de desenvolvimento de aprendizagens da Matemática. Esse movimento de imersão na escola, ao longo do estágio, contribuiu para a formação inicial do futuro professor de Matemática e para a constituição de sua identidade docente.

Palavras-chave: Estágio Supervisionado, Formação do Professor, Matemática, Identidade Docente.

\section{INTRODUÇÃO}

O presente artigo, recorte do Trabalho de Conclusão de Curso da primeira autora, trata de apresentar as reflexões acerca das experiências vividas em um estágio de observação em que o estagiário atua como observador e investigador da prática docente e das questões que ocorrem na escola. Durante o processo de observação o estagiário se aproxima dos conteúdos, da prática docente, da realidade da escola e sala de aula, o que é de suma importância para a construção do seu conhecimento profissional. De acordo com Pimenta e Lima (2004, p. 55) "o estágio, então, deixa de ser considerado apenas um dos componentes e mesmo um apêndice do currículo e passa a integrar o corpo de conhecimento do curso de formação de professores".

Nessa direção, portanto, o estágio torna-se indispensável para a formação do Professor de Matemática, sendo um dos espaços para a vivência daquilo que se aprende na Universidade e, para muitos, o primeiro contato com a futura profissão. É como sinalizaram Suzart e Silva (2020), um espaço pendular de articulação entre teoria e prática, não a percebendo de forma desarticulada.

$\mathrm{RC}: 100185$

Disponível em: https://www.nucleodoconhecimento.com.br/educacao/estagio-de-observacao 
Importante salientar, ainda partindo do que discutimos anteriormente, que essa experiência ajuda a entender e conviver com a realidade da profissão, entrar em contato com a sala de aula, a vivência no âmbito escolar, a realidade professor/aluno e vários aspectos pertinentes à profissão. Ainda sobre o que apontamos, para Lima; Kegler e Broch (2019, p. 170) esse período de estágio se consolida na maneira de articular teoria e prática no exercício da docência, contribuindo no processo de formação e desenvolvendo um conjunto de saberes para a futura prática.

Há, ainda hoje e por parte de muitos estudantes, uma visão equivocada sobre a Matemática. Muitos a percebem como algo que não serve para as diversas atividades cotidianas; a enxerga como algo difícil ou, como eles mesmos enunciam: "um bicho de sete cabeças". Perceber essas imagens construídas e entender como elas se fundamentam para os estudantes nos permitirá corrigi-las futuramente, até porque compreendemos ser esse, como bem nos apresentou D’Ambrósio (1993), um dos principais desafios do educador matemático do século XXI. Observar como o ensino da Matemática é vivenciado em sala de aula da Educação Básica é importante para o movimento de constituição da identidade docente e é por isso que esse estágio, de uma forma particular, faz-se tão necessário: saímos do lugar de aluno, como bem evidenciou Correia e Silva (2020), para o de professor [ou de futuro professor].

Retomando o que D’Ambrósio (1993) evidenciou e que destacamos anteriormente, sobre o desafio posto aos educadores matemáticos, importa-nos destacar que a Matemática vai muito além de apenas números sem sentido. Pelo contrário; faz parte de nosso dia a dia e é assim que precisa ser percebido pelos estudantes. E isso, embora pareça algo simples de se fazer é algo desafiador, sobretudo, pela situação em que se encontra a educação brasileira e pelas dificuldades que se arrastam ano a ano de escolarização, no que tange ao ensino e aprendizagem

RC: 100185

Disponível em: https://www.nucleodoconhecimento.com.br/educacao/estagio-de-observacao 
dessa ciência, e que se acentuaram agora com o contexto de pandemia, como evidenciaram Silva, Nery e Nogueira (2020) e Silva (2021).

Embora a experiência que resultou na escrita deste texto tenha ocorrido antes do período pandêmico, onde encontros presenciais eram possíveis; a produção deste manuscrito seguiu ao longo do ano de 2020 e, por isso, sofreu influência de literatura produzida sobre os impactos da pandemia para a educação. Mas, além disso, é importante destacar que a nossa forma de perceber as coisas mudou desde que a experiência foi vivenciada. Todo esse distanciamento e demais situações promovidas pelo contexto de pandemia nos fez perceber as coisas de uma forma diferente de como víamos antes. Porém, uma coisa não mudou: "é importante que o professor entenda que a Matemática estudada deve de alguma forma, ser útil aos alunos, ajudando-os a compreender, explicar ou organizar sua realidade". (D'AMBROSIO, 1993, p. 35).

O componente curricular obrigatório Estágio Supervisionado I, do curso de Licenciatura em Matemática da Universidade do Estado da Bahia, possui 75 horas; dessas 45 destinam-se a observação na escola e às 30 horas restantes para leituras, discussões e encontros na universidade, juntamente com o professor orientador e os demais participantes do estágio.

O Estágio aconteceu em uma escola pública da região norte do Estado da Bahia, no segundo semestre do ano de 2019. Nesse período foram trabalhados, pelo professor supervisor, os assuntos: i) Circunferência e Círculo; ii) Ângulo Central; iii) Setor Circular; iv) Gráfico de Setores; v) Porcentagem; vi) Divisão da Circunferência; vii) Divisão do Círculo em Setores. Importa considerar que alguns encontros foram contextualizados com a temática da "Consciência Negra", devido ao dia da Consciência Negra. A carga horária destinada às atividades na escola foi dividida entre observação das aulas, atividades da escola e leitura do Projeto Político Pedagógico - PPP.

RC: 100185 
O presente artigo, portanto, elege como questão norteadora para a escrita: como o movimento de estagiar, sobretudo em um estágio de observação, influencia a constituição da identidade docente? Objetiva-se apresentar, aqui, as reflexões originadas desse contato com a escola campo de estágio, durante o período de observação, buscando olhar para esse espaço enquanto importante para o movimento de constituição da identidade docente. O estágio, partindo do que evidenciaram Pimenta (1999) e Pimenta e Lima (2004), assume esse lugar de pesquisa e contribui para a constituição, também, do professor pesquisador. Esse trabalho, particularmente e pela especificidade do objetivado, assume-se de natureza qualitativa e tem, enquanto instrumentos de produção de dados: a) observação e registros no diário de bordo construído; b) análise ao PPP da escola; c) conversas informais com os membros da comunidade escolar; d) questionário aplicado com o professor supervisor.

\section{A ESCOLA PARCEIRA}

O Estágio de Observação foi realizado em uma turma de oitavo ano de uma escola pública. A escola pertence à rede de ensino de um município da região norte do Estado da Bahia, parte do Território de Identidade Piemonte Norte do Itapicuru. A instituição possui 33 funcionários, sendo eles: um diretor, uma coordenadora pedagógica, dois secretários, um digitador, dezessete professores, uma cuidadora de estudantes deficientes, dois ajudantes de sala, quatro merendeiras efetivas e três contratadas e uma professora de Educação Especial.

A escola campo de estágio escolhida, também chamada de escola parceira, atende aos públicos de Educação Infantil e Ensino Fundamental, distribuídos da seguinte forma nos turnos: no matutino atende-se o Ensino Fundamental, do $3^{\circ}$ ao 9ํano; e no vespertino atende-se a Educação Infantil e do $1^{\text {우 }}$ ao $5^{\circ}$ ano do Ensino Fundamental. São 46 alunos matriculados na Educação Infantil; 166 nos anos

RC: 100185

Disponível em: https://www.nucleodoconhecimento.com.br/educacao/estagio-de-observacao 
iniciais do Ensino Fundamental e 80 nos anos finais do Ensino Fundamental, totalizando 292 alunos.

A estrutura física da escola: uma cozinha, cinco banheiros (quatro para os alunos e um para os professores), um pátio coberto, um pátio livre, sete salas de aula, uma sala especial (pra estudantes com deficiência), uma secretaria, uma pequena biblioteca, uma sala para digitar provas, um depósito e uma sala de professores. A escola dispõe de água canalizada, energia elétrica, boa iluminação e ventilação (arcondicionado em algumas salas).

A escola não dispõe, por exemplo, de um laboratório de informática ou de um laboratório de educação Matemática. Entendemos serem esses espaços importantes para o movimento de ensino e aprendizagem da Matemática, como sinalizou Silva (2020) e, sobretudo, para a inclusão desses estudantes na era digital, algo que se mostrou tão necessário agora no período de pandemia, como destacado por Silva, Nery e Nogueira (2020). Além dos espaços aos quais nos referimos anteriormente, vale destacar que a escola não possui quadra esportiva. Os estudantes utilizam, quando necessário, a quadra de uma praça que fica em frente à instituição. A pequena biblioteca, durante o período de estágio, não foi utilizada pelo professor supervisor.

Lamentavelmente percebemos, ao longo de nossas observações e conversas informais com direção, coordenação e professores e professoras de Matemática aos quais tivemos contato, bem como da análise ao PPP da escola, que não há projetos envolvendo a Matemática e outras áreas do conhecimento; e infelizmente não possui laboratório de ensino que potencialize o movimento de matematizar. Todas as salas são utilizadas e a escola tem parceria com a Escola Mista Militar visando, como sinaliza a escola, à melhoria da aprendizagem dos alunos. Durante todos os dias observados a escola dispôs de merenda e água.

RC: 100185

Disponível em: https://www.nucleodoconhecimento.com.br/educacao/estagio-de-observacao 
Vale destacar, quando questionados sobre a construção do Projeto Político Pedagógico (PPP), fomos informados que o mesmo foi construído de forma coletiva, com todo o corpo docente e coordenação da escola. Trata-se de um documento que identifica a escola e suas principais demandas, servindo de base para a construção de um ambiente democrático.

A escola tem uma boa estrutura física, apesar de o espaço ser pequeno para a quantidade de estudantes que recebe. No pátio livre professores e alunos fizeram uma horta, que serve para a escola, alunos e demais membros da comunidade que precisar. Nessa direção, portanto, a escola além de ensinar assume o seu lugar enquanto bem social, servindo aos alunos e à comunidade de diversas formas. Nesse sentido, como nos afirma Coelho e Orzechowski (2011, p. 16324), "[...] e se pensarmos pelo bem comum de todos vamos ver que a escola é um bem social, ela é para todos $[\ldots]$.

De acordo com o PPP da escola o recurso financeiro recebido é o do Programa de Desenvolvimento Educacional - PDE e Programa Dinheiro Direto na Escola PDDE. Esses recursos são recebidos pela escola e utilizados em suas prioridades: realiza a compra de material didático, equipamentos de uso pedagógico, formação dos professores e melhoria da infraestrutura física e pedagógica.

Infelizmente, pelo que percebemos durante o nosso período de observação, há algumas necessidades a serem atendidas no que tange a infraestrutura da escola: algumas portas não têm mais maçanetas; os banheiros não têm uma boa estrutura para atender estudantes com deficiência e nem foram pensados para o público infantil, por exemplo. Entendemos que os estudantes precisam estudar em um ambiente acolhedor e que favoreça o movimento de ensino e aprendizagem. Segundo Coelho e Orzechowski (2011, p. 16324) "a ação social e, no caso, a ação social da escola, sobre o sujeito é tão forte, que ela consegue se fixar no sujeito de 
forma tão marcante que muitas vezes ele, mesmo inconscientemente vai se moldando a proposta escolar".

Durante a leitura do PPP percebemos indicativos de ações que buscavam aproximar a família da escola, entendendo-os como importantes para o processo educacional e buscando estratégias para que se reconhecessem como tal. Uma das ações impetradas pela instituição seria a realização de reuniões frequentes com familiares, algo significativo para o desenvolvimento do aprendizado. No entanto, um dos principais problemas encontrados na escola, mesmo com as tentativas dessas ações, é com a baixa frequência dos pais a essas reuniões. Durante as quarenta e cinco horas de observação, presenciamos apenas uma mãe foi até a escola para saber sobre o comportamento e desenvolvimento do filho.

\section{VIVÊNCIAS DO ESTÁGIO}

Nesta seção focaremos na apresentação das experiências oriundas do contato da primeira autora com a escola parceira e nas reflexões sobre esse contato para o movimento de constituição da identidade docente. Vale destacar que, pela natureza narrativa desse item, optamos pela escrita em primeira pessoa. Tratar-se-á, portanto, do olhar da estudante ao seu período de observação. Em alguns momentos usar-se-á a terceira pessoa para explanar sobre construções e conjecturas realizadas com autores ou com o coautor deste texto, professor orientador do estágio e do TCC da estudante.

O estágio de observação teve início no dia dezessete de setembro de dois mil e dezenove, em uma turma de oitavo ano, matutino, que tinham matriculados quatorze estudantes, sendo cinco meninos e nove meninas. As aulas aconteciam segundafeira (duas aulas), quinta-feira (uma aula) e sexta-feira (duas aulas).

RC: 100185

Disponível em: https://www.nucleodoconhecimento.com.br/educacao/estagio-de-observacao 
Antes de iniciar o estágio, fui à escola entregar o ofício de apresentação e conhecer o professor supervisor e demais membros da comunidade escolar. Conhecemos-nos e então recebi o cronograma de horários das aulas. O primeiro dia foi na quinta-feira. Seria somente uma aula no terceiro horário, mas com receio de ocorrer horários vagos e a aula ser adiantada ou antecipada fui desde o primeiro. Chegando à escola observei algo que me deixou intrigada: todos os alunos estavam no pátio, em fileiras e em seguida receberam reclamação em relação ao comportamento em sala de aula. Logo após rezaram, cantaram o Hino Nacional e foram "dispensados" para a sala de aula. Dirigi-me à sala dos professores e esperei chegar o horário da aula.

Assim que chegou o horário fui, juntamente com o professor supervisor para a sala; ao entrarmos todos os alunos levantaram e um deles entoou a frase: "Atenção turma, apresento o Professor" e todos num coro: "Bom dia, professor!" e assim se repetiu comigo. $O$ professor me apresentou à turma e fui muito bem recebida. Ele iniciou o assunto Círculo e Circunferência. A aula foi explicativa, com atividade escrita utilizando como recurso a lousa, livro didático e piloto. Iniciou o assunto mostrando na lousa e com auxílio do livro didático a diferença entre círculo e circunferência e suas respectivas características, em seguida aplicou a atividade escrita. Não houve dúvidas por parte dos estudantes, não manifestas nesse dia.

Na sexta-feira, dia da próxima aula, se repetiu o mesmo processo de apresentação que relatei anteriormente e isso me deixou intrigada. Nesse sentido senti-me motivada e perguntei a vice-diretora do que se tratava. Segundo ela a escola tem parceria com a Escola Mista Militar, visando melhoria no comportamento e aprendizado dos alunos. Isso, de certa forma, me fez pensar: Em que entoar essas frases de ordem vai contribuir no processo de ensino e aprendizagem da Matemática? Existe diferença entre medo e respeito? Para além da disciplina, qual a interferência militar nos movimentos de ensino e aprendizagem? Os militares envolvidos com a escola têm formação pedagógica? Fiquei me questionando sobre isso, nunca tinha participado de nada dessa natureza.

RC: 100185

Disponível em: https://www.nucleodoconhecimento.com.br/educacao/estagio-de-observacao 
Ainda na sexta o professor corrigiu a atividade do dia anterior e passou para turma outra, onde os alunos usaram as duas aulas do dia para resolver. A atividade foi escrita, grande e repetitiva. Apesar de não apresentarem dúvidas, durante a explicação do assunto, ao circular pela sala percebi que os estudantes estavam achando a atividade proposta chata e repetitiva, pois já haviam resolvido uma parecida na aula anterior. Isso me fez pensar sobre o futuro e sobre o como poderia fazer com a turma; várias ideias e materiais surgiram em minha cabeça para explicar o assunto. Toda essa situação fez-me refletir que nós, enquanto professores de Matemática, já sabendo dessa percepção que muitos estudantes construíram dessa ciência enquanto "chata", precisamos utilizar a criatividade para que esse pensamento seja ressignificado.

Ainda sobre a discussão anterior, vale destacar que precisamos estimular os nossos estudantes à prática da pesquisa; mas para isso precisamos ser professores pesquisadores (SILVA e OLIVEIRA, 2020). Nesse ínterim, D‘Ambrósio (1993, p. 3536) nos alerta de que nossos estudantes não vêm à Matemática como dinâmica, criativa e com emoção e que é importante para nós professores pensarmos em menos acúmulo de informação e mais ação, pesquisa e produção, para que aconteça de fato a aprendizagem matemática durante o matematizar. No final deste dia recebemos o comunicado do diretor de que mesmo que tenham aulas vagas as outras aulas não poderiam ser adiantadas, e a partir desse dia comecei a ir somente aos horários das aulas.

Depois de alguns encontros e conversas com o professor supervisor e orientador comecei a resgatar algumas escritas que fiz no diário de bordo, na tentativa de traçar um perfil da turma observada. Observei que do total de estudantes tem um grupo de oito meninas que interagem com o resto da turma; um grupo dos cinco meninos e uma menina que ficam no canto da sala e raramente participam da aula. Em relação a esse grupo dos que não participam; principalmente a aluna, observei que o professor quase nunca a procura para saber os motivos de sua não RC: 100185 
participação. Durante o estágio, pelo menos, não o vi aproximando-se da mesma, algo diferente dos demais. Perguntei-me: Mas por quê? No grupo das oito meninas tem uma líder, é a líder da sala; ela fica responsável por todas as tarefas e avisos destinados à turma. Percebi que alguns alunos, exceto a que raramente interage com a turma, resolvem suas atividades pela dela e se tem alguma dúvida se reportam também a ela. No grupo dos meninos há dois deles que geralmente atrapalhavam a aula por conversarem muito.

Foi de suma importância poder ter observado a dinâmica da sala de aula, convivido com os alunos e observado a postura do professor em relação à sala nesse período de observação. Nesse primeiro contato com essa realidade de sala de aula pude perceber que tipo de professora de Matemática eu pretendo ser e essa experiência de formação propôs isso. Importante perceber, enquanto observador pesquisador, as diferentes situações que acontecem e prever possíveis reações nossas. Nesse período de observação, várias problemáticas eram postas e algumas delas eu socializei como perguntas aqui neste artigo. Elas foram por demais importantes para a minha formação. Nessa direção, segundo Pimenta (1999, p.18)

Espera-se, pois, que mobilize os conhecimentos da teoria da educação e da didática necessários à compreensão do ensino como realidade social, e que se desenvolva neles a capacidade de investigar a própria atividade para, a partir dela, constituírem e transformarem os seus saberes-fazeres docentes, num processo contínuo de construção de suas identidades como professores.

De uma forma geral cabe considerar que a turma é dedicada aos estudos. Embora a maioria das aulas observadas destinou-se a explicação de conteúdo e atividades complementares, com uso apenas do quadro, o professor usava a criatividade e trazer, de vez em quando, atividades práticas como, por exemplo, uma que considerei interessante: quando o professor supervisor ia trabalhar com circunferência, ensinar como dividi-la em partes iguais, utilizou compasso, transferidor e uma folha de papel. Essa atividade consistia em encontrar o meio da

RC: 100185

Disponível em: https://www.nucleodoconhecimento.com.br/educacao/estagio-de-observacao 
folha de papel e esse meio também seria o centro da circunferência. Depois de encontrado e feito a circunferência usando o centro da folha, fez-se dobradura na mesma e essa dobradura ia dividindo a circunferência em partes iguais, na medida em que dividiam eles utilizavam o transferidor e mediam os graus. Foi uma atividade simples, mas que fizeram os estudantes pensarem, vivenciarem, perceber que seria possível dividi-la em partes iguais e aprenderem alguns conceitos.

Via-se, claramente, o envolvimento dos estudantes nesse tipo de aula, como a que falamos anteriormente e, como também aconteceu nas experiências de Vieira e Silva (2020) e Souza et al. (2020). Percebi, de verdade, que os alunos se interessavam mais por aulas nesse contexto: mais dinâmico e problematizador. Como salienta D'Ambrosio (1993, p. 36), o que o aluno testemunha, muitas vezes durante aulas de Matemática, é uma solução bonita, eficiente, sem obstáculos e sem dúvidas, dando-lhe a impressão de que ele também deverá conseguir resolver problemas matemáticos com tal elegância. Temos que permitir ao estudante o prazer da descoberta, da pesquisa, tentativa e dos prazeres e desafios do matematizar.

Observei que na escola foi adotado um fardamento, não somente para os alunos, mas também para os professores. Era uma camisa com o emblema do município e a imagem da mascote da escola e calça. Sobre a relação do professor com a turma: observei que o professor tem um controle de sala excelente e busca em alguns momentos métodos diferentes de ensino. Fiquem observando, também, que embora tenha a aparência de "durão", é respeitado e amigo dos alunos.

As aulas, quase sempre, eram desenvolvidas com assunto e atividades complementares. Na maioria das vezes, nos dias em que tinham duas aulas, o professor passava assunto e após a explicação e resolução de alguns exercícios, passava atividades para serem resolvidas na sala. Nos dias em que tinha somente uma aula ele corrigia as atividades passadas e passava outras para os alunos

RC: 100185

Disponível em: https://www.nucleodoconhecimento.com.br/educacao/estagio-de-observacao 
resolverem em casa. Não recebi nenhum planejamento de aula do professor durante as observações. Ter contato com esses planejamentos era algo importante, pois entendemos que a construção de planos de aula ultrapassa o atendimento de uma demanda burocrática e vai ao encontro de uma dimensão de ação política e pedagógica, como bem evidenciaram Silva et al. (2014).

Mesmo sem receber os planejamentos de aula era perceptível que o professor ia para a sala preparo e seguro do que estava ensinando, o que é importante para um professor. Daí fiquei pensando, sobretudo após a leitura do texto de Silva et al. (2014), que mais que planejar, o professor tem que fazer com que o planejamento aconteça de fato. O planejamento facilita a aula e ajuda o professor na hora de executá-la. Nesse sentido é possível perceber que o ato de planejar está presente no nosso dia a dia e que professores de Matemática precisam pensar que é primordial no momento de pensar na aula e no processo de ensino e aprendizagem da Matemática.

Os instrumentos avaliativos utilizados pelo professor supervisor foram atividades escritas e provas. Entendemos que a avaliação é de suma importância para a educação e que ela não é somente para o estudante, mas também para o professor se avaliar, como asseveraram Costa e Albuquerque (2015). Lembro-me de um momento que ocorreu na sala de aula e eu achei interessante: todos os estudantes se reuniram na mesa do professor querendo saber suas notas. Houve, em sala, diversas atividades escritas durante a unidade e eles queriam que todas essas atividades valessem nota, inclusive a apresentação do Dia da Consciência Negra.

Pelas experiências observadas na avaliação ficou nítido, para nós, que se valoriza no espaço escolar as atividades escritas. Não houve, durante o percurso, a utilização de algum outro instrumento. Muitas vezes, instrumentos desse tipo, priorizam a repetição e não a descoberta matemática. Algumas vezes fica a impressão de que certo tipo de avaliação favorece a construção do pensamento

RC: 100185

Disponível em: https://www.nucleodoconhecimento.com.br/educacao/estagio-de-observacao 
errôneo de que a Matemática "não serve pra nada", como ouvimos algumas vezes em sala. Temos que ter em mente, como professores de Matemática, que "o objetivo é o aprendizado e não o resultado final” (COSTA; ALBUQUERQUE, 2015, p. 34).

Os estudantes da sala quando resolviam alguma atividade, recorriam ao professor e perguntavam se a resolução estava correta, se estivesse ele sinalizava positivamente e caso contrário ele dizia que não ou dizia como resolver sem que o aluno tivesse a possibilidade de encontrar o resultado por caminhos próprios. Eles voltavam para seus lugares, apagavam o que fizeram e tentavam refazer, em seguida faziam o mesmo processo de procurar o docente, o que ficava claro uma falta de confiança e dependência do professor. Observei que não há um acompanhamento nesse processo do erro ao acerto o que é essencial para o processo ensino e aprendizagem. Segundo Vergani (1993), citado por Costa e Albuquerque (2015, p. 31), “interessar-se pelo aluno é interessar-se pelos seus erros. Assim, os erros não podem ser apenas assinalados, mas devem ser objeto de um trabalho específico do professor com o estudante". Foi isso que sentimos falta durante o estágio.

\section{CONSIDERAÇÕES FINAIS}

Quando pensava que seria professora logo vinha em mente diversos desafios que enfrentaria em sala de aula, seja na realização de aula ou a minha relação com os próprios estudantes. Tudo parecia difícil, o medo de estar à frente dos estudantes e não conseguir fazê-los aprender; a preocupação da imagem que iria passar; do exemplo que iria ser, enfim, várias inquietações me atormentavam. Quando comecei a estagiar tudo isso mudou. Passar por essa experiência foi fundamental para meu aprendizado, formação e constituição da identidade docente. As reflexões e debates originados nos encontros coletivos, na Universidade, foram importantes para essa ressignificação.

RC: 100185

Disponível em: https://www.nucleodoconhecimento.com.br/educacao/estagio-de-observacao 
Durante o processo de estágio tive a oportunidade de vivenciar momentos bons e prazerosos com os estudantes. Um dos momentos marcantes foi o projeto sobre o Dia da Consciência Negra. Todas as turmas participaram e cada uma ficou responsável por um tema. Nesse processo me pediram para ajudar e eu aceitei. Houve uma aproximação positiva entre a turma e eu. No dia da culminância do projeto nos divertimos bastante e levo comigo esse momento e creio que foi significativo para os estudantes também.

O estágio contribuiu de forma positiva para a construção do conhecimento pedagógico e pedagógico do conteúdo, e foi de fundamental importância para que eu me percebesse enquanto futuro professor de Matemática. Conviver com os estudantes e com o professor na sala de aula me fez perceber que realmente é isso que quero pra minha vida profissional. Terei desafios durante a minha jornada, mas faz parte da vida. O medo que tinha da sala de aula passou e, apesar de ter sido um estágio de observação, pude perceber o quão prazeroso e desafiador é ensinar.

Essa experiência, portanto, contribuiu de forma grandiosa para minha formação. Pude ver como conduzir a aula, ter a oportunidade de pensar em metodologias apropriadas para diferentes situações de ensino, algo que me deixava preocupada antes; e pude perceber que a relação professor/aluno vai muito além de ministrar aula apenas, é uma relação de parceria, de amizade, de construção de vida, compartilhamento de aprendizado.

\section{REFERÊNCIAS}

COELHO, Nara; ORZECHOWSKI, Suzete Terezinha. A Função Social da Escola Pública e suas Interfaces. X Congresso Nacional de Educação, Curitiba, 2011.

RC: 100185 
CORREIA, Vinícius Cristhian Pinho; SILVA, Américo Junior Nunes da. O Estágio e a Formação do Professor de Matemática. Revista Brasileira De Educação Básica, v. 5 , p. 1-8, 2020.

COSTA, Andréia Alves da; ALBUQUERQUE, Leila Cunha de. Avaliação da Aprendizagem Matemática na perspectiva dos processos avaliativos utilizados por professores do Ensino Fundamental anos finais. Periódico Científico Projeção e Docência | v.6, n.2, 2015.

D'AMBROSIO, Beatriz. Formação de Professores de Matemática para o Século XXI: o Grande Desafio. Pro-Posições Vol. 4 №. 1 [10]. 1993.

LIMA, Kadja Silveira; KEGLER, Natália Alessandra; BROCH, Siomara Cristina. VIVÊNCIAS DE ESTÁGIO DE OBSERVAÇÃO NO ENSINO FUNDAMENTAL. Educação Matemática em Revista, Brasília, v. 24, n. 62, p. 166-177, abr./jun. 2019.

PIMENTA, Selma Garrido. Formação de professores: identidade e saberes da docência. In: PIMENTA, Selma Garrido. (Org.). Saberes pedagógicos e atividade docente. São Paulo: Cortez Editora, 1999. p.15 a 34.

PIMENTA, Selma Garrido; LIMA, Maria Socorro Lucena. Estágio e Docência. Revisão técnica: José Cerchi Fusari, São Paulo: Cortez, 2004. - (Coleção docência em formação. Série saberes pedagógicos).

SILVA, Américo Junior Nunes da; SOUZA, Ilvanete dos Santos de; BARROS, Simone Santos; ALMEIDA, Jeferson Dias. O Professor de Matemática e o Ato de Planejar: Há Unicidade entre Dimensão Política e Dimensão Pedagógica?. In: Américo Junior Nunes da Silva; Ilvanete dos Santos de Souza. (Org.). A Formação do Professor de Matemática em Questão: Reflexões para um Ensino com Significado. 1ed.Jundiaí: Paco Editorial, 2014, v. 1, p. 39-52. 
SILVA, Américo Junior Nunes da; OLIVEIRA, Caique Melo. A Pesquisa $\mathrm{Na}$ Formação Do Professor De Matemática. Revista Internacional De Formação De Professores (RIPF), v. 5, p. 1/ e020015-23, 2020.

SILVA, Américo Junior Nunes da Silva. Professores de Matemática em Início de Carreira e os Desafios (Im)postos pelo Contexto Pandêmico: um Estudo de Caso com Professores do Semiárido Baiano. Revista Ibero-Americana de Humanidades, Ciências e Educação. v. 07. n. 01. 2021.

SILVA, Américo Junior Nunes da. O Laboratório de Educação Matemática e a Formação Inicial de Professores de Matemática. Revista Internacional Educon, [S. I.], v. 1, n. 1, p. e20011001, 2020. DOI: 10.47764/e20011001. Disponível em: https://grupoeducon.com/revista/index.php/revista/article/view/14. Acesso em: 24 jan. 2021.

SOUZA, Paloma; SOUZA; Kennedy; SILVA, Raiane; SILVA, Américo Junior Nunes da. Reflexões acerca da vivência do jogo "batalha naval no plano cartesiano" em uma turma de matemática nos anos finais do ensino fundamental. Ágor@ - Revista Acadêmica De Formação De Professores, v. 4, p. 1-13, 2020.

SUZART, Leonardo Araújo; SILVA, Américo Junior Nunes da. O Estágio Supervisionado E O Constituir-Se Professor De Matemática: "Ser ou não ser professor?". Educação Básica Revista, [S. I.], v. 6, n. 1, p. p.131-141, 2020. Disponível em: http://www.educacaobasicarevista.com.br/index.php/ebr/article/view/4. Acesso em: 24 jan. 2021.

VIEIRA, Evaldo Silva; SILVA, Américo Junior Nunes da Silva. Dominó Fracionário: uso do material didático para o ensino de frações. Mundo Livre: Revista Multidisciplinar Discente, v. 6, p. 134-146, 2020.

RC: 100185

Disponível em: https://www.nucleodoconhecimento.com.br/educacao/estagio-de-observacao 
Enviado: Janeiro, 2021.

Aprovado: Novembro, 2021.

RC: 100185

Disponível em: https://www.nucleodoconhecimento.com.br/educacao/estagio-de-observacao 